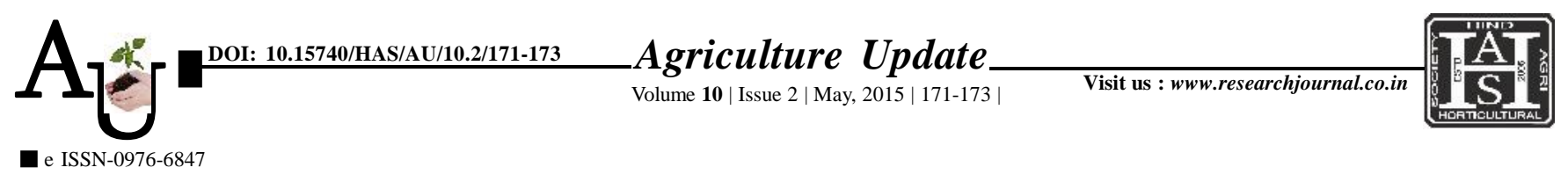

\title{
Research Note: Extent of adoption of recommended production technology of potato by potato growers
}

\section{VAISHALI. R. SHITRE*, PARMESHWARI B. PAWAR AND B.M. PATEL}

Article Chronicle: Received : 09.03.2015;

Accepted :

22.04.2015

KEY Words :

Adoption,

Recommended

production

technology, Potato

growers
SUMMARY : The present study was carried out during the year 2009-10 in Anand district of Gujarat state, to assess the extent of adoption of recommended production technology of potato by potato growers. The study revealed that majority of the potato growers belonged to medium level of adoption. Most of potato growers were found in non-adaptor category in respect of certain important items like chemical weed control and disease control. So as to enhance adoption, it is necessary to involve the farmers in extension education programme. It would facilitate the dissemination of recent technologies.

How to cite this article : Shitre, Vaishali. R., Pawar, Parmeshwari B. and Patel, B.M. (2015). Extent of adoption of recommended production technology of potato by potato growers. Agric. Update, 10(2): 171-173. 